\title{
FAKTOR RISIKO KELELAHAN PADA TKBM (TENAGA KERJA BONGKAR MUAT DI PELABUHAN BELAWAN
}

\author{
Rosmidah Simanjuntak ${ }^{1)^{*}}$, Masni $^{2)}$ \\ 1. Prodi D-3 Farmasi STIKes Indah Medan \\ 2. Prodi D-3 Keperawatan STIKes Indah Medan \\ *Email: rosmidahsimanjuntak@gmail.com
}

\begin{abstract}
Abstrak
Pekerja TKBM (Tenaga Bongkar Muat) merupakan salah satu jenis pekerjaan yang berisiko mengalami kelelahan fisik dan mengakibatkan penurunan kesejahteraan. Tujuan penelitian ini untuk mengetahui faktor risiko kelelahan pada TKBM (Tenaga Kerja Bongkar Muat) di Pelabuhan Belawan. Penelitian ini merupakan penelitian kuantitatif analitik korelasi dengan menggunakan pendekatan desain cross sectional. Populasi dalam penelitian adalah seluruh pekerja TKBM dan sampel dalam penelitian sebanyak 40 orang. Analisis data menggunakan uji chi-square dan uji regresi logistik berganda Hasil penelitian tentang analisis faktor risiko kelelahan pada TKBM di Pelabuhan Belawan adalah usia ( $\mathrm{p}=0$,047), durasi kerja $(p=0,021)$ dan beban kerja $(p=0,005)$ terhadap kelelahan pada TKBM di Pelabuhan Belawan. Kesimpulan dalam penelitian ini adalah faktor risiko secara signifikan penyebab kelelahan pada di Pelabuhan Belawan antara lain usia, durasi kerja, dan beban kerja. Perlu dilakukan upaya adanya Safety Talk tentang kelelahan, penyebab kelelahan, dan akibat dari kelelahan pada tenaga kerja bongkar muat di Pelabuhan Belawan agar para pekerja dapat memperoleh pengetahuan dalam menjaga kesehatan tubuh mereka.
\end{abstract}

Kata kunci : Kelelahan, Usia, Durasi kerja, Beban Kerja, Kelelahan

\begin{abstract}
Fatigue Risk Factors at TKBM (Unloading Workers) at Belawan Port. TKBM workers (Tenaga Unloading) is one type of work that is at risk of experiencing physical fatigue and resulting in a decrease in welfare. The purpose of this study was to determine the risk Fatigue Risk Factors at TKBM (Unloading Workers) at Belawan Port. factors for fatigue in TKBM (Unloading Workers) at Belawan Port. This research is correlation analytic quantitative research using a crosssectional design approach. The population in the study were all TKBM workers and the sample in the study was 40 people. Data analysis using chi-square test and multiple logistic regression A. The results of the study on the analysis of fatigue risk factors at TKBM in Belawan Port were age $(p=0.047)$, work duration $(p=0.021)$ and workload $(p=0.005)$ on fatigue TKBM at Belawan Port. The conclusion in this study is that the risk factors that significantly cause fatigue at the Port of Belawan include age, duration of work, and workload. Efforts need to be made to have a Safety Talk about fatigue, causes of fatigue, and the effects of fatigue on loading and unloading workers at Belawan Port so that workers can gain knowledge in maintaining their body health.
\end{abstract}

Keywords: Fatigue, Age, Duration of Work, Workload, Fatigue 


\section{Pendahuluan}

\begin{abstract}
Kelelahan kerja merupakan suatu permasalahan tentang proses yang mengakibatkan penurunan kesejahteraan, kapasitas atau kinerja akibat dari aktivitas
\end{abstract} kerja yang mempengaruhi baik kesehatan maupun keselamatan kerja yang dapat menjadi faktor risiko terjadinya kecelakaan pada saat bekerja (Halajur, 2019). Hasil penelitian yang dilakukan oleh Zhang (2016) dalam penelitiannya menyatakan bahwa kelelahan merupakan salah satu kondisi yang disebut silent killer (Gong et al., 2016). Hasil penelitiannya menunjukkan terdapat hubungan bermakna antara kelelahan dengan kecelakaan pada pengemudi bus. Hasil penelitian pada pengendara ojek online di Kota Tomohon menyatakan hal yang sama bahwa salah satu penyebab kecelakaan kerja adalah kelelahan (Tanriono, Doda, \& Manampiring, 2019).

Kelelahan kerja disebabkan oleh banyak faktor baik dari faktor individu dan juga faktor dari luar seperti lingkungan sendiri (Gurusinga, Camelia, \& Purba, 2015). Kelelahan menunjukkan kondisi yang berbeda-beda pada setiap individu, tetapi semua berawal pada kehilangan efisiensi dan penurunan kapasitas kerja dan ketahanan tubuh yang ditandai dengan perasaan lemah, output menurun, dan kondisi fisiologis yang dihasilkan dari aktivitas terus menerus (Tarwaka, 2004). Jenis kelelahan ada bermacam-macam, salah satu jenis dari kelelahan adalah kelelahan otot. Kelelahan otot ditandai dengan tremor atau rasa nyeri yang terdapat pada otot (Soedirman, 2014).

Kelelahan kerja memiliki gejala kelelahan secara subjektif dan objektif seperti perasaan lesu, ngantuk, pusing, kurang mampu berkonsentrasi, berkurangnya tingkat kewaspadaan, persepsi yang buruk atau lambat dan tidak ada atau berkurangnya gairah untuk bekerja (Cahyani, 2016). Pada saat tubuh melakukan aktivitas, tubuh memerlukan energi yang diperoleh dari pembakaran zat makanan. Energy yang diperoleh dari proses tersebut digunakan oleh otot untuk melakukan kontraksi dan relaksasi . energi pada kontraksi yang diperoleh dari perubahan adenosine triphosphate (ATP) kemudian ADP diubah kembali menjadi ATP oleh energi yang tersedia dari pemecahan glikogen. Adegan tambahan persediaan oksigen maka pemecahan bersifat aerob, yang menghasilkan karbondioksida dan air. Deplesi ATP dan phospocreatin mengakibatkan terjadinya kelelahan otot (Watson, 2002). Bila tidak cukup tersedia oksigen akan pecah menjadi asam laktat (glycogen anaerobic) dan kadar asam laktat dalam darah akan bertambah. Akumulasi asam laktat dalam aliran darah dapat mengurangi kapasitas kerja otot yang 
selanjutnya akan mengakibatkan kondisi yang disebut kelelahan (Winarsunu, 2008).

Faktor yang menyebabkan kelelahan antara lain usia, durasi kerja, masa kerja, beban kerja, status gizi dan faktor lainnya (Kusgiyanto \& Ekawati, 2017). Semakin bertambahnya umur akan semakin rentan terjadinya kelelahan hal ini dikarenakan terjadinya penurunan kekuatan dan ketahanan otot (Ferusgel, Butar-Butar, Widya, Napitupulu, \& Chaniago, 2020). Pada umur 40-49 tahun kondisi penurunan mulai terlihat dari ditemukannya diagnosa-diagnosa penyakit dan pada usia 50-55 tahun kapasitas kerja seseorang akan menurun (Budiman, Husaini, \& Arifin, 2016). Hasil penelitian menunjukkan bahwa pekerja dengan usia $>45$ tahun berisiko mengalami kelelahan dibandingkan dengan usia yang lebih muda (Nedine Putri Watulinggas \& Lestari, 2019). Masa kerja adalah waktu yang dihitung berdasarkan tahun pertama bekerja hingga saat penelitian dilakukan dihitung dalam tahun. Semakin lama masa kerja seseorang maka semakin tinggi juga tingkat kelelahan, karena semakin lama bekerja menimbulkan perasaan jenuh akibat kerja monoton akan berpengaruh terhadap tingkat kelelahan yang dialami (Asriyani \& Karimuna, 2017). Semakin tinggi beban kerja maka akan meningkatkan konsumsi oksigen secara proporsional sampai didapat kondisi maksimumnya. Beban kerja yang lebih tinggi yang tidak dapat dilaksanakan dalam kondisi aerobic, disebabkan oleh kandungan oksigen yang tidak mencukupi untuk suatu proses aerobic. Akibatnya adalah manifestasi rasa lelah (Utami, 2012). Status gizi berhubungan dengan kelelahan. atus gizi optimal adalah keseimbangan antara asupan zat gizi dengan kebutuhan zat gizi.Status gizi merupakan salah satu penyebab kelelahan. Seorang tenaga kerja dengan keadaan gizi yang baik akan memiliki kapasitas kerja dan ketahanan tubuh yang lebih baik, begitu juga sebaliknya (Herliani, 2012).

Pekerja TKBM (Tenaga Bongkar Muat) merupakan salah satu jenis pekerjaan yang berisiko mengalami kelelahan fisik. Karena setiap harinya tenaga kerja ini bertugas memindahkan barang dari gudang penyimpanan ke kendaraan yang mengangkut barang-barang sampai di dermaga, setelah barang telah berada di dermaga pekerjaan dilanjutkan dengan mengangkat atau mengangkut barang dari kendaraan masuk ke dalam kapal dengan menggunakan tenaga manual atau tenaga dari tubuh mereka sendiri. Jam kerja pekerja salaam 2 jam termasuk istirahat 1 jam untuk kegiatan bongkar muat pada setiap giliran kerja. Berdasarkan hasil wawancara kepada 5 orang TKBM didapatkan bahwa secara keseluruhan pernah mengalami perasaan berat di kepala, kaki terasa berat, menguap, mengantuk, merasa berat pada 
mata,kadang-kadang tidak konsentrasi dalam bekerja, sakit kepala, bahu kaku dan merasa pusing saat bekerja dan juga masuk angin. Tujuan penelitian ini untuk mengetahui faktor risiko kelelahan pada TKBM (Tenaga Kerja Bongkar Muat) di Pelabuhan Belawan.

\section{Metode}

Penelitian ini merupakan penelitian kuantitatif analitik korelasi dengan menggunakan pendekatan desain cross sectional. Penelitian ini bertujuan untuk mengetahui keeratan hubungan antara variabel yang diteliti tanpa melakukan intervensi. Penelitian dilaksanakan di Pelabuhan Belawan. Sumber data dalam penelitian ini sumber data primer yang diambil langsung dari responden baik menggunakan kuesioner dan menggunakan alat ukur. Data sekunder berasal dari data dari Pelabuhan Belawan. Populasi dalam penelitian adalah seluruh pekerja TKBM dan sampel dalam penelitian sebanyak 40 orang. Instrumen dalam penelitian ini menggunakan kuesioner, alat timbang badan dan alat ukur tinggi badan, alat ukur denyut nadi dan alat ukur asam laktat. Variabel independen dalam penelitian ini adalah usia, durasi kerja, masa kerja, beban kerja dan kelelahan., sedangkan variabel dependen adalah kelelahan. Analisis data menggunakan uji chi-square dan uji regresi logistik berganda. Izin etik penelitian No: 13/kEPK/UNPRI/I/2021

\section{Hasil}

Hasil analisis deskriptif dalam penelitian ini terdiri dari usia, durasi kerja, masa kerja, beban kerja, status gizi dan kelelahan. Hasil penelitian menunjukkan bahwa mayoritas usia responden pada kategori usia < 45 tahun sebanyak24 orang $(60,0 \%)$ sedangkan pada usia $\geq 45$ tahun orang (40,0\%). Pada variabel durasi kerja mayoritas responden bekerja selama $<8$ jam sebanyak 23 orang $(57,5 \%)$ dan $\geq 8$ jam sebanyak 17 orang (42,5\%). Pada variabel masa kerja mayoritas responden bekerja selama $\geq 5$ tahun sebanyak 30 orang $(57,5 \%)$ dan $<5$ tahun sebanyak 10 orang $(25,0 \%)$. Pada variabel beban kerja kategori ringan dan berat sama-sama sebanyak 20 orang. 50,0\%). Pada variabel status gizi mayoritas responden pada kategori status gizi normal sebanyak 27 orang $(67,5 \%)$ dan pekerja yang pada status gizi kurus maupun gemuk sebanyak 13 orang (32,5\%). Pada variabel kelelahan mayoritas pekerja lelah sebanyak 23 orang $(57,5 \%)$., dapat dilihat pada tabel berikut ini: 
Tabel 1 . Distribusi Frekuensi Berdasarkan usia, durasi kerja, masa kerja, beban kerja, status gizi dan kelelahan pada TKBM di Pelabuhan Belawan

\begin{tabular}{|c|c|c|}
\hline Variabel & $\mathbf{n}$ & $\%$ \\
\hline \multicolumn{3}{|l|}{ Usia } \\
\hline$<45$ Tahun & 24 & 60,0 \\
\hline$\geq 45$ Tahun & 16 & 40,0 \\
\hline \multicolumn{3}{|l|}{ Durasi Kerja } \\
\hline$<8$ jam & 23 & 57,5 \\
\hline$\geq 8$ jam & 17 & 42,5 \\
\hline \multicolumn{3}{|l|}{ Masa Kerja } \\
\hline$<5$ Tahun & 10 & 25,0 \\
\hline$\geq 5$ Tahun & 30 & 75,0 \\
\hline \multicolumn{3}{|l|}{ Beban Kerja } \\
\hline Ringan & 20 & 50,0 \\
\hline Berat & 20 & 50,0 \\
\hline \multicolumn{3}{|l|}{ Status Gizi } \\
\hline Normal & 27 & 67,5 \\
\hline $\begin{array}{l}\text { Tidak Normal (kurus/ } \\
\text { gemuk) }\end{array}$ & 13 & 32,5 \\
\hline \multicolumn{3}{|l|}{ Kelelahan } \\
\hline tidak lelah & 17 & 42,5 \\
\hline Lelah & 23 & 57,5 \\
\hline Total & 40 & 100,0 \\
\hline
\end{tabular}

Analisis hubungan antara usia responden, durasi kerja, masa kerja, beban kerja dan status kerja dengan kelelahan kerja pada TKBM di Pelabuhan Belawan. Hasil uji statistik menggunakan uji chi-square menunjukkan usia dengan nilai $\mathrm{p}=0,037<0,05$, durasi kerja dengan nilai $\mathrm{p}=0,037<0,05$, masa kerja dengan nilai $\mathrm{p}=0,009<0,05$, beban kerja dengan nilai $\mathrm{p}=0,000<0,05$ yang berarti ada hubungan antara usia, durasi kerja, masa kerja dan beban kerja dengan kelelahan pada TKBM di Pelabuhan Belawan Tahun 2021.

Tabel 2. Tabulasi Silang Faktor yang Berhubungan dengan Kelelahan pada TKBM di Pelabuhan Belawan

\begin{tabular}{|c|c|c|c|c|c|c|c|}
\hline \multirow{3}{*}{ Variabel } & \multicolumn{4}{|c|}{ Kelelahan Kerja } & \multirow{2}{*}{\multicolumn{2}{|c|}{ Jumlah }} & \multirow{3}{*}{ Sig-p } \\
\hline & \multicolumn{2}{|c|}{ Tidak lelah } & \multicolumn{2}{|c|}{ Lelah } & & & \\
\hline & $\mathbf{f}$ & $\%$ & $\mathbf{f}$ & $\%$ & $f$ & $\%$ & \\
\hline \multicolumn{8}{|l|}{ Usia Responden } \\
\hline$<45$ Tahun & 14 & 35,0 & 10 & 25.0 & 24 & 60,0 & \multirow[t]{3}{*}{0,013} \\
\hline$\geq 45$ Tahun & 3 & 17,5 & 13 & 32,5 & 16 & 40,0 & \\
\hline Total & 17 & 42,5 & 23 & 57,5 & 40 & 100,0 & \\
\hline \multicolumn{8}{|l|}{ Durasi Kerja } \\
\hline$<8$ jam & 13 & 32,5 & 10 & 25,5 & 23 & 57,5 & \multirow[t]{2}{*}{0,037} \\
\hline$\geq 8$ jam & 4 & 10,0 & 13 & 32,5 & 17 & 42,5 & \\
\hline
\end{tabular}




\begin{tabular}{|c|c|c|c|c|c|c|c|}
\hline Total & 17 & 42,5 & 23 & 57,5 & 40 & 100,0 & \\
\hline \multicolumn{8}{|l|}{ Masa Kerja } \\
\hline$<5$ Tahun & 8 & 20,0 & 2 & 5,0 & 10 & 25,0 & 0,009 \\
\hline$\geq 5$ Tahun & 9 & 22,5 & 21 & 52,2 & 30 & 75,0 & \\
\hline Total & 17 & 42,5 & 23 & 57,5 & 40 & 100,0 & \\
\hline \multicolumn{8}{|l|}{ Beban Kerja } \\
\hline Ringan & 14 & 35,0 & 6 & 15,0 & 20 & 50,0 & 0,000 \\
\hline Berat & 3 & 7,5 & 17 & 42,5 & 20 & 50,0 & \\
\hline Total & 17 & 42,5 & 23 & 57,5 & 40 & 100,0 & \\
\hline \multicolumn{8}{|l|}{ Status Gizi Kerja } \\
\hline Normal & 13 & 32,5 & 14 & 35,0 & 27 & 67,5 & 0,298 \\
\hline $\begin{array}{l}\text { Tidak Normal } \\
\text { (kurus/gemuk) }\end{array}$ & 4 & 10,0 & 9 & 22,5 & 13 & 32,5 & \\
\hline Total & 17 & 42,5 & 23 & 57,5 & 40 & 100,0 & \\
\hline
\end{tabular}

Analisis faktor risiko kelelahan pada TKBM di Pelabuhan Belawan adalah usia $(\mathrm{p}=0,047)$, durasi kerja $(\mathrm{p}=0,021)$ dan beban kerja $(\mathrm{p}=0,005)$ terhadap kelelahan pada TKBM di Pelabuhan Belawan.

Tabel 3. Faktor Risiko Kelelahan pada TKBM di Pelabuhan Belawan

\begin{tabular}{lcc}
\hline \multicolumn{1}{r}{ Variabel } & \multicolumn{1}{c}{ B } & \multicolumn{1}{c}{ Sig. } \\
\hline Usia & 2.051 & .047 \\
Durasi Kerja & 2.467 & .021 \\
Beban Kerja & 2.802 & .005 \\
Constant & -2.690 & \\
\hline
\end{tabular}

\section{Pembahasan}

Kelelahan kerja merupakan bagian dari permasalah umum yang sering dijumpai. Hasil penelitian menunjukkan bahwa mayoritas TKBM di Pelabuhan Belawan yaitu sebesar 57,5\%. Indikator kelelahan pada TKBM seperti gejala pelemahan aktivitas yang dialami pekerja yaitu lelah pada seluruh badan kaki terasa berat, sering menguap, susah konsentrasi, merasa ngantuk, dan keinginan berbaring. Hasil ini sesuai dengan penelitian yang dilakukan oleh Ainun Naim yang dilakukan pada tenaga kerja bongkar muat di pelabuhan sebesar 53,3\%. Kelelahan kerja juga diindikasikan dengan kepala pusing, hilang konsentrasi, motivasi berkurang. Hal ini juga dapat menyebabkan resiko kecelakaan kerja pada TKBM (Naim, 2020). Hasil penelitian lain yang dilakukan Rutriar juga mengatakan hal yang sama yaitu kelelahan kerja yang dialami oleh supir bus trayek Makassar-Toraja diperoleh bahwa pekerja yang mengalami kelelahan lebih banyak dibandingkan pekerja yang tidak mengalami kelelahan (Labi, 2017). Kelelahan kerja pada TKBM lebih condong pada kelelahan otot karena harus memikul beban muatan setiap harinya. Kelelahan kinerja otot setelah terjadinya tekanan melalui fisik untuk suatu waktu disebut kelelahan otot secara fisiologi, dan gejala yang ditunjukan tidak hanya berupa berkurangnya tekanan fisik, namun juga pada 
semakin rendahnya gerakan. Pada akhirnya kelelahan fisik ini dapat menyebabkan sejumlah hal yang kurang menguntungkan seperti: melemahnya kemampuan tenaga kerja dalam melakukan pekerjaannya dan meningkatnya kesalahan dalam melakukan kegiatan kerja, sehingga dapat mempengaruhi produktivitas kerjanya, seperti kuantitas pengangkutan bongkar muat menurun ataupun mengalami kecelakaan kerja seperti terjatuh pada saat mengangkat muatan.

Hasil penelitian juga menunjukkan bahwa umur termasuk faktor risiko kelelahan pada TKBM di Pelabuhan Belawan dengan nilai $\mathrm{p}=0,047<0,05$. Hal ini dimungkinkan karena pada usia tua kerja otot mengalami penurunan sehingga mempengaruhi kualitas kelelahan pada pekerja. Hal ini juga disebabkan pada orang dengan kategori umur tua telah terjadi perubahan jaringan tubuh, dimana semakin tua umur seseorang maka akan menyebabkan kekuatan tubuh berkurang sehingga cepat merasakan kelelahan (Tarwaka, 2004). sejalan dengan penelitian yang dilakukan oleh Rutriar Tahun 2017 menyatakan bahwa terdapat terdapat hubungan antara umur dengan kelelahan pada supir bus Trayek Makassar-Toraja (Labi, 2017). Penelitian terbaru yang dilakukan di Semarang juga memiliki kesimpulan yang sama yaitu ada hubungan antara usia dengan kelelahan kerja pada tenaga kerja bongkar muat bagian pemanggul pupuk di pelabuhan Tanjung Mas Semarang (Medianto, 2017).

Pada pekerja TKBM di Pelabuhan belawan terkadang jam kerja juga melebihi 8 jam/ hari tergantung dari mandor masingmasing apakah borongan atau tidak. Jika sistem borongan jam kerja pada TKBM bisa melebihi dari 8 jam/ hari. Hasil penelitian menunjukkan bahwa durasi kerja umur termasuk faktor risiko kelelahan pada TKBM di Pelabuhan Belawan dengan nilai $\mathrm{p}=0,047<$ 0,05. Hal ini terjadi karena Circardium rhythm (keadaan alamiah tubuh) yang terganggu seperti tidur, kesiapan untuk bekerja dan banyak proses otonom lainnya yang seharusnya beristirahat pada malam hari karena pekerjaan yang menuntut kerja lembur maka proses dalam tubuh dipaksa untuk siaga dalam bekerja, hal ini akan meningkatkan asam laktat dalam tubuh dan menimbulkan kelelahan kerja. Penelitian ini sejalan dengan penelitian yang dilakukan oleh Penelitian yang dilakukan oleh Daniel Carlos menyatakan bahwa durasi mengemudi, kualitas tidur, dan beban kerja waktu memiliki hubungan dengan kelelahan kerja (Carlos, Yasnani, \& Afa, 2017). Penelitian yang dilakukan Irma pada tahun 2014 pada unit produksi Paving Block CV.Sumber Galian Kecamatan Biringkanaya Kota Makassar (Irma, Syamsiar, \& Andi, 2014). Dalam seminggu seseorang biasanya dapat bekerja dengan baik selama 40-50 jam 
(Prastuti, Sintia, \& Ningsih, 2020). Lebih dari itu, kemungkinan besar untuk timbulnya hal yang negatif bagi tenaga kerja yang bersangkutan

Dalam seminggu seseorang biasanya dapat bekerja dengan baik selama 40-50 jam (Prastuti et al., 2020). Lebih dari itu, kemungkinan besar untuk timbulnya hal yang negatif bagi tenaga kerja yang bersangkutan (Anisyah \& Saptadi, 2019). Hasil penelitian menunjukkan bahwa beban kerja merupakan faktor risiko yang paling dominan yang menyebabkan kelelahan pada TKBM di Pelabuhan Belawan. Semakin besar tingkat beban kerja pada TKBM maka semakin tinggi resiko kelelahan kerja. Berdasarkan hasil observasi, aktivitas kerja TKBM yang panjang dan tanggung jawab yang besar dalam mengangkut muatan dimana juga harus menjaga kemasan muatan harus tetap baik. Oleh karena itu dengan pekerjaan yang sifatnya berat membutuhkan istirahat yang sering dan waktu kerja yang pendek. Jika waktu kerja ditambah maka melebihi kemampuan tenaga kerja dan akan menimbulkan kelelahan. Penelitian pekerja kantor di Uni Emirat Arab (UAE) pada tahun 2013 menunjukan adanya hubungan antara beban kerja dengan kelelahan kerja (Usman \& Yuliani, 2019). penelitian Ika Putri juga sesuai dengan penelitian ini dimana didapatkan $\mathrm{p}$ value $=0,040$, sehingga dapat dijelaskan bahwa terdapat korelasi antara beban kerja dengan kelelahan kerja pada tenaga kerja bongkar muat di Pelabuhan Samudera Bitung (Andiani, Kawatu, \& Ratag, 2018). Buruh angkut merupakan salah satu pekerjaan yang sangat perlu diperhatikan karena pekerjaan ini mempunyai banyak risiko terhadap kesehatan pekerja. Pada umumnya pekerja tersebut harus menggunakan tubuh sebagai alat angkut seperti memikul, menjinjing, maupun memanggul. Pekerjaan mengangkat dan mengangkut jika dilakukan dengan tidak benar maka akan berpotensi berbahaya seperti menimbulkan terjadinya kecelakaan kerja dan penyakit akibat kerja semakin meningkat.

\section{Kesimpulan}

Kesimpulan dalam penelitian ini adalah faktor risiko secara signifikan penyebab kelelahan pada TKBM (Tenaga Kerja Bongkar Muat) di Pelabuhan Belawan antara lain usia, durasi kerja, dan beban kerja. Sedangkan masa kerja dan status gizi bukan merupakan faktor risiko yang signifikan penyebab kelelahan pada TKBM di Pelabuhan Belawan. Perlu dilakukan upaya adanya Safety Talk tentang kelelahan, penyebab kelelahan, dan akibat dari kelelahan pada tenaga kerja bongkar muat di Pelabuhan Belawan agar para pekerja dapat memperoleh pengetahuan dalam menjaga kesehatan tubuh mereka. 


\section{Referensi}

Andiani, I. P., Kawatu, P. A. T., \& Ratag, B. T. (2018). Hubungan Antara Beban Kerja Dan Asupan Kalori Dengan Kelelahan Kerja Pada Tenaga Kerja Bongkar Muat Di Pelabuhan Samudera Bitung. KESMAS, 7(4).

Anisyah, T. D. A., \& Saptadi, J. D. (2019). Hubungan Antara Waktu Kerja Dan Beban Kerja Fisik Dengan Perasaan Kelelahan Pada Pekerja Di Home Industri Tahu Di Dukuh Janten, Kabupaten Bantul. DISS, Universitas Ahmad Dahlan.

Asriyani, N., \& Karimuna, S. R. (2017). Faktor yang Berhubungan dengan Terjadinya Kelelahan Kerja pada Pekerja PT. Kalla Kakao Industri Tahun 2017. (Jurnal Ilmiah Mahasiswa Kesehatan Masyarakat), 2(6).

Budiman, A., Husaini, H., \& Arifin, S. (2016). Hubungan antara Umur dan Indeks Beban kerja dengan Kelelahan pada Pekerja di PT. Karias Tabing Kencana. Jurnal Berkala Kesehatan, 1(2), 121129.

Cahyani, W. D. (2016). Hubungan antara beban kerja dengan kelelahan kerja pada pekerja buruh angkut. Pena Jurnal Ilmu Pengetahuan Dan Teknologi, 19(2).

Carlos, D., Yasnani, Y., \& Afa, J. R. (2017). Faktor-Faktor yang Berhubungan dengan Kelelahan Pengemudi Truk Tangki di Terminal Bbm PT. Pertamina (Persero) Kec. Latambaga Kab. Kolaka Tahun 2016. Jurnal Ilmiah Mahasiswa Kesehatan Masyarakat, 1(4).

Ferusgel, A., Butar-Butar, M. H., Widya, A., Napitupulu, L. H., \& Chaniago, A. D. (2020). Risk Factors of an Online Motorcycle Taxi (Ojek Online) Fatigue in Medan. In 5th Universitas Ahmad Dahlan Public Health Conference (UPHEC 2019) (pp. 76-80). CONF, Atlantis Press.

Gong, Z., Zhang, G., Zeng, X., Li, J., Li, G.,Huang, W., ... Wong, C. (2016).
High-strength, tough, fatigue resistant, and self-healing hydrogel based on dual physically cross-linked network. ACS Applied Materials \& Interfaces, 8(36), 24030-24037.

Gurusinga, D., Camelia, A., \& Purba, I. G. (2015). Analisis Faktor-Faktor yang Berhubungan dengan Kelelahan Kerja pada Operator Pabrik Gula PT. PN VII Cinta Manis Tahun 2013. Jurnal Ilmu Kesehatan Masyarakat, 6(2).

Halajur, U. (2019). Promosi Kesehatan di tempat kerja. BOOK, WINEKA MEDIA.

Herliani, F. (2012). Hubungan Status Gizi dengan Kelelahan Kerja pada Pekerja Industri Pembuatan Gamelan di Daerah Wirun Sukoharjo. JOUR.

Irma, M. R., Syamsiar, S. R., \& Andi, W. (2014). Faktor yang Berhubungan dengan Kelelahan Kerja pada Unit Produksi Paving Block CV. Sumber Galian Kecamatan Biringkanaya Kota Makassar. Jurnal. Makassar: Universitas Hasanuddin.

Kusgiyanto, W., \& Ekawati, E. (2017). Analisis Hubungan Beban Kerja Fisik, Masa Kerja, Usia, Dan Jenis Kelamin Terhadap Tingkat Kelelahan Kerja Pada Pekerja Bagian Pembuatan Kulit Lumpia Di Kelurahan Kranggan Kecamatan Semarang Tengah. Jurnal Kesehatan Masyarakat (E-Journal), 5(5), 413-423. JOUR.

Labi, R. R. (2017). Faktor Yang Berhubungan Dengan Kelelahan Kerja Pada Supir Bus Trayek Makassar-Toraja Tahun 2017.

Medianto, D. (2017). Faktor-Faktor yang Berhubungan dengan Kelelahan Kerja pada Tenaga Kerja Bongkar Muat (TKBM) di Pelabuhan Tanjung Emas Semarang (Studi Pada Pekerja TKBM Bagian Unit Pengantongan Pupuk). DISS, Muhammadiyah University of Semarang.

Naim, A. (2020). Perilaku Pekerja Tenaga Kerja Bongkar Muat Pelabuhan. HIGEIA (Journal of Public Health 
Research and Development), 4(Special 1), 215-226.

Nedine Putri Watulinggas, V., \& Lestari, M. (2019). Analisis Faktor-Faktor Yang Berhubungan Dengan Kelelahan Kerja Pada Tenaga Kerja Bongkar Muat Di Pelabuhan Boom Baru Palembang Tahun 2019. DISS, Sriwijaya University.

Prastuti, B., Sintia, I., \& Ningsih, K. W. (2020). Hubungan Lama Kerja dan Posisi Duduk Terhadap Kejadian Low Back Pain Pada Penjahit di Kota Pekanbaru. Jurnal Endurance: Kajian Ilmiah Problema Kesehatan, 5(2), 375382.

Soedirman, S. P. K. (2014). Keselamatan Kerja Dalam Perspektif Hiperkes dan Keselamatan Kerja. Erlangga Medical Series. JOUR.

Tanriono, Y., Doda, D. V., \& Manampiring, A. E. (2019). Hubungan Kelelahan Kerja, Kualitas Tidur, Perilaku Pengemudi, dan Status Gizi dengan Kecelakaan Kerja pada Pengemudi Ojek di Kota Bitung. KESMAS, 8(6).

Tarwaka, Pgd. (2004). Ergonomi Industri Dasar-dasar Pengetahuan dan Aplikasi di Tempat Kerja Edisi II. JOUR.

Usman, S., \& Yuliani, I. (2019). Faktor-Faktor yang Berhubungan Dengan Kelelahan Kerja pada Karyawan Produksi PT Gerbang Sarana Baja Jakarta Utara. Journal Educational of Nursing (JEN), 2(1), 141-146. JOUR.

Utami, A. R. D. (2012). Hubungan Antara Beban Kerja Dan Intensitas Kebisingan Dengan Kelelahan Pada Tenaga Kerja Pemeliharaan Jalan Cisalak Kotabima $\mathrm{Cv}$ Serayu Indah Cilacap. DISS, Universitas Negeri Semarang.

Watson, R. (2002). Anatomi\& Fisiologi. CONF, EGC.

Winarsunu, T. (2008). Psikologi keselamatan kerja. Malang: UPT Penerbitan Universitas Muhammadiyah Malang. 